Article

\title{
Conversion of Carbohydrates into Platform Chemicals Catalyzed by Alkaline Ionic Liquids
}

\author{
Xiaojia Du, Jie Zhang *, Yuehai Wang and Yongshui Qu \\ State Key Laboratory of Chemical Resource Engineering, Beijing University of Chemical Technology, \\ Beijing 100029, China; 2015210001@buct.edu.cn (X.D.); 2015210006@buct.edu.cn (Y.W.); \\ quyongshui@126.com (Y.Q.) \\ * Correspondence: zhangjie@mail.buct.edu.cn; Tel.: +86-10-644-12054
}

Received: 19 June 2017; Accepted: 18 August 2017; Published: 23 August 2017

\begin{abstract}
A series of alkaline ionic liquids (ILs) including 1-butyl-3-methylimidazolium benzoate ([BMIM]PHCOO), 1-butyl-3-methylimidazolium carbonate ([BMIM] $\left.]_{2} \mathrm{CO}_{3}\right)$, 1-butyl-3methylimidazolium acetate ([BMIM]OAc), 1-butyl-3-methylimidazolium hydroxide ([BMIM]OH), ethanolamine tetrafluoroborate ([MEA] $\left.\mathrm{BF}_{4}\right)$, and 1,1,3,3-tetramethylguanidine (TMG)-based ILs, etc., were synthesized and utilized as catalysts for the conversion of carbohydrates into 5-HMF.

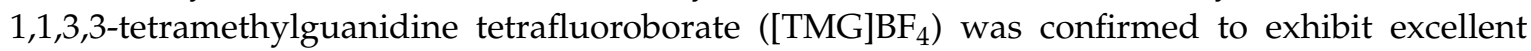
catalytic activity, and was much cheaper than other ILs such as 1-butyl-3-methylimidazolium chloride $([\mathrm{BMIM}] \mathrm{Cl})$ for use as a solvent in the conversion of $\mathrm{C}_{6}$ carbohydrates into 5-HMF. The 5-HMF yields from fructose, glucose, cellobiose, and microcrystalline cellulose (MCC) were $74.19 \%, 27.33 \%, 20.20 \%$, and $17.73 \%$, respectively. In addition, the possible pathway of carbohydrates (MCC, cellobiose, glucose, etc.) conversion into 5-HMF with [TMG] $\mathrm{BF}_{4}$ as a catalyst was speculated, and the conversion of glucose into 5-HMF was determined to likely be the committed step in the transformation of MCC

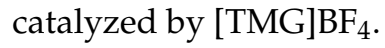

Keywords: alkaline ionic liquids; conversion of carbohydrates; 5-HMF; [TMG]BF 4

\section{Introduction}

The continuous depletion of conventional fossil fuel resources and the risk of global climate change have forced researchers to search for alternative sustainable energy resources [1-3]. Biomass has emerged as a potential sustainable source of energy and organic chemicals, which can gradually replace petroleum. Lignocellulosic biomass is mainly composed of monosaccharide and disaccharide carbohydrates (fructose, glucose, galactose, mannose, sucrose, and cellobiose) and lignin. Several researchers have investigated the efficient conversion of carbohydrates into high value-added chemicals, such as 5-hydroxymethylfurfural (5-HMF), levulinic acid (LA), formic acid (FA), acetic acid, furfural, etc. [4-6]. Of these primary chemicals, 5-HMF is known as one of the most important platform chemicals of the proposed biomass-derived carbohydrates (Scheme 1). The US Department of Energy has already declared it to be among the "top 10 bio-based chemicals" [7]. This chemical is highly reactive and thus can be used as a starting material for a number of products. Studies show that fructose, as ketose, can more easily be dehydrated to 5-HMF than glucose [8-14]. However, fructose is an expensive starting material for 5-HMF production compared to glucose. The use of glucose and cellulose (the most widespread natural polymer materials) cannot only significantly reduce the production cost of 5-HMF, but will improve the utilization efficiency of biomass. Therefore, many investigations have been carried out in this field. Recently, ionic liquids (ILs) have emerged as excellent reaction media due to their nonvolatility, nonflammability, high polarity, and their facile isolation of products for the synthesis of inorganic compounds, thereby offering an alternative to other solvents $[15,16]$. Zhang et al. [17] first observed that ILs resulted in nearly $70 \%$ yield of 5-HMF from 
glucose when $\mathrm{CrCl}_{2}$ was used as a catalyst. Since then, halides, $\mathrm{H}$-form zeolites, transition metal ions, strong acid cation exchange resin, etc. have been used as catalysts for the production of HMF from glucose, sucrose, cellulose, and other carbohydrates using different ILs as solvents or co-solvents [18]. Meanwhile, Valente et al. [15] carried out a comparative study with ILs as co-solvents in a biphasic system by adding $\mathrm{CrCl}_{3}$ to investigate the selectivity of glucose dehydration to HMF. Shi et al. [19] investigated the direct conversion of cellulose into 5-HMF using concentrated $\mathrm{NaHSO}_{4}$ and $\mathrm{ZnSO}_{4}$ as co-catalysts in a biphasic system, and observed $53 \mathrm{~mol} \%$ yield of 5-HMF. Zuo [20] investigated the dehydration of fructose conversion to $5-\mathrm{HMF}$ by using homogeneous and heterogeneous Brönsted acids, and found that higher 5-HMF yields were produced through lower concentrations of inorganic acid (extremely-low $\mathrm{HCl}$ and $\mathrm{H}_{2} \mathrm{SO}_{4}, 90.3 \%$ and $82.8 \%$, respectively); however, the conversion of 5-HMF to byproducts was enhanced in this solvent system [21]. Moreover, the interaction between DMSO and carbohydrates also benefited the conversion of carbohydrates to 5-HMF [22]. In this case, higher HMF yields can be easily achieved by only using a small amount of IL catalyst.

Han et al. [10] increased HMF production catalyzed by Lewis acid $\left(\mathrm{SnCl}_{4}\right)$, using 1-ethyl-3methylimidazolium tetrafluoroborate $\left([\mathrm{EMIM}] \mathrm{BF}_{4}\right)$ as a solvent, with a mass ratio of ILs to glucose set at 4.34. In addition, Ståhlberg et al. [4] used lanthanides as catalysts in glucose conversion to 5-HMF in dialkylimidazolium chlorides. The highest yield of 5-HMF turned out to be $24 \%$ when the strongest Lewis acids, triflate and ytterbium chloride, were used simultaneously. However, this 5-HMF yield was much lower than that catalyzed by $\mathrm{CrCl}_{2}$, which was $70 \%$ [17]. Additionally, Zhao [23] studied the dehydration of glucose into 5-HMF using a microwave irradiation environment. ILs yielded 40\% 5-HMF when applied in the presence of Cr-HAP (hydroxyapatite-supported chromium chloride). On the other hand, Li et al. [24] achieved 5-HMF yields of $24.6 \%$ and $30.8 \%$ in a one-pot cellulose-to-HMF conversion process using self-synthesized functional polymeric ILs (FPILs) by coupling $\mathrm{SO}_{3} \mathrm{H}$-functionalized polymeric ILs with different counterpart anions with/without $\mathrm{CrCl}_{3}-6 \mathrm{H}_{2} \mathrm{O} . \mathrm{Cr}\left([\mathrm{PSMIM}] \mathrm{HSO}_{4}\right)_{3}$ was designed and observed to be an effective catalyst in degrading cellulose with [BMIM]Cl as a solvent [25]. The cellulose conversion of $95 \%$ was obtained in a reaction containing $0.05 \mathrm{~g} \mathrm{Cr}\left([\mathrm{PSMIM}] \mathrm{HSO}_{4}\right)_{3} / 2.0 \mathrm{~g}$ [BMIM]Cl, with a mass ratio of ILs to MCC of 20 , at $120{ }^{\circ} \mathrm{C}$ for $5 \mathrm{~h}$, and the maximum yield of 5-HMF and total reducing sugars (TRS) was $53 \%$ and $94 \%$, respectively.

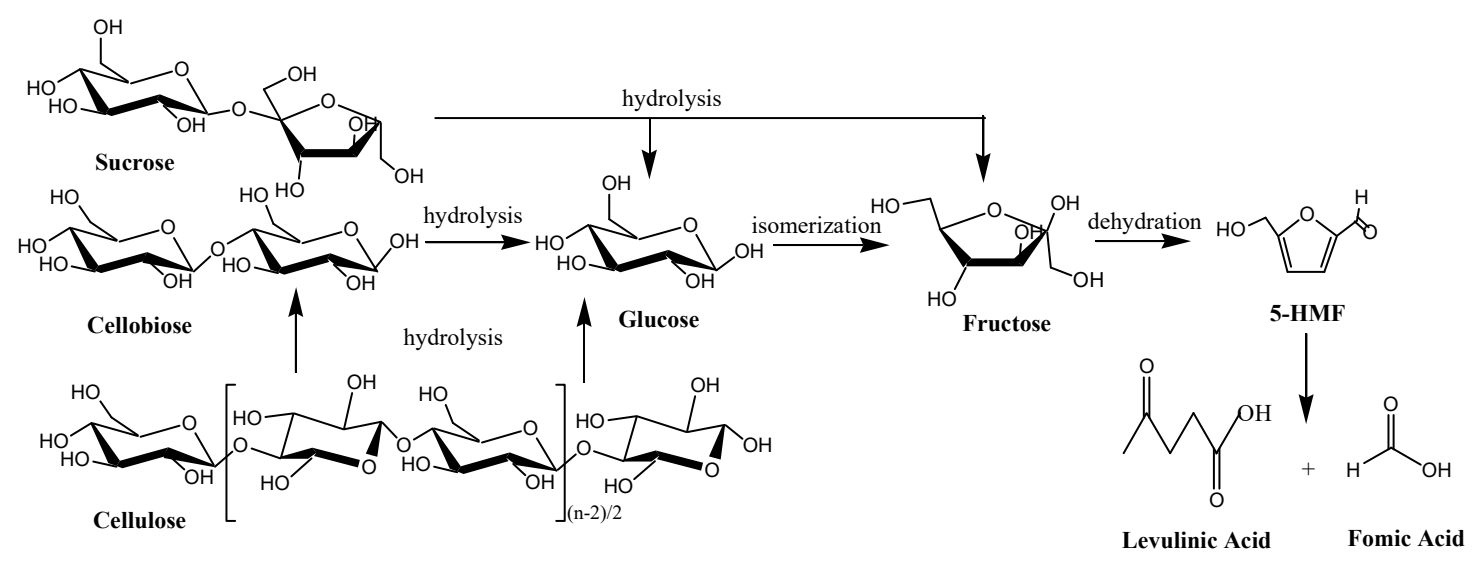

Scheme 1. Conversion of carbohydrates into 5-HMF.

However, the aforementioned studies mainly used ILs as solvents or co-solvents, which require high volume of ILs [15-18]. ILs are expensive compounds and their use in high volumes cause 5-HMF production to become economically unfeasible. Moreover, 5-HMF recovery from the reaction mixture further renders the overall process uneconomical. Besides cost effectiveness, this process causes environmental pollution due to the use of chromate as a catalyst in current conversion systems. 
In order to make the process more competitive and feasible, Tong et al. [26] recently used $\mathrm{N}$-methyl-2-pyrrolidonium methyl sulfonate ([NMP][C $\left.\mathrm{CH}_{3} \mathrm{SO}_{3}\right], 7.5 \mathrm{~mol} \%$ ) as a catalyst in the conversion of fructose into 5-HMF, and achieved a yield of $72.3 \%$. Unfortunately, the 5-HMF yield from glucose was only $3.0 \%$, which was much lower than that from the $\mathrm{CrCl}_{2} /[\mathrm{BMIM}] \mathrm{Cl}$ process [17]. An investigation made by Tian et al. [27] obtained a 5-HMF yield of $69.1 \%$ from glucose with a $\mathrm{SnCl}_{4}$-tetrabutyl ammonium bromide $\left(\mathrm{SnCl}_{4}\right.$-TBAB)/DMSO system at $100{ }^{\circ} \mathrm{C}$ for $2 \mathrm{~h}$ under atmospheric pressure. Moreover, $\mathrm{SnCl}_{4}-\mathrm{TBAB}$ was also used in the conversion of sucrose and cellulose with 5-HMF yields of $66.4 \%$ and $4.3 \%$. The dehydration of monosaccharides (fructose and glucose) to produce 5-HMF has been systematically investigated by employing ILs as catalysts in our previous studies [28-30]. Although it has been proved effective, the feedstock was confined to monosaccharides, and fructose has been identified as the most easily converted feedstock. Since the structure of the natural biomass is far more complex than that of the monosaccharides, it is not enough to scale up 5-HMF production using biomass as feedstock. It is then necessary to investigate more carbohydrates with complex structures for their conversion into 5-HMF. In addition, most of the ILs used as catalysts were limited by their acidic nature. More ILs, particularly neutral and alkaline ones, need to be tested in this conversion process.

In this study, the feasibility of 5-HMF production from glucose, fructose, sucrose, cellobiose, and microcrystalline cellulose (MCC) was investigated using different ILs as catalysts including 1-butyl-3-methylimidazolium benzoate ([BMIM]PHCOO), 1-butyl-3-methylimidazolium carbonate $\left([\mathrm{BMIM}]_{2} \mathrm{CO}_{3}\right)$, 1-butyl-3-methylimidazolium acetate ([BMIM]OAc), 1-butyl-3-methylimidazolium hydroxide ([BMIM]OH), ethanolamine tetrafluoroborate ([MEA] $\left.\mathrm{BF}_{4}\right)$, and 1,1,3,3-tetramethylguanidine (TMG)-based IL were synthesized. The appropriate ILs were identified and the conversion mechanism was suggested.

\section{Results and Discussion}

\subsection{Materials and Experimental Methods}

MCC (VIVAPUR-105) was provided by JRS Company (Rosenberg, Germany). It was sieved and MCC with the size of 180-200 $\mu \mathrm{m}$ was employed as feedstock. Glucose, fructose, and cellobiose were purchased from Sigma Aldrich Company (St. Louis, MO, USA).

1,1,3,3-tetramethylguanidinium, lactic acid, $N$-methylimidazole were purchased from Beijing Da Tian Feng Tuo Chemical Reagent Company (Beijing, China). 5-HMF was purchased from Shanghai Jingchun Chemical Reagent Company (Shanghai, China); Sucrose, $\mathrm{KOH}$, methylbenzene, dichloromethane, bromobutane, toluene, ether, ethyl acetate, dimethylsulfoxide (DMSO), and $\mathrm{N}, \mathrm{N}$-dimethylacetamide (DMAc) containing lithium chloride $(\mathrm{LiCl})$ were purchased from Beijing Chemical Reagent Company (Beijing, China). All the reagents were used as received.

The procedure preparing [TMG] $\mathrm{BF}_{4}$ was performed as follows [31]: Tetrafluoroboric acid ( $40 \mathrm{wt} \%, 4.39 \mathrm{~g}, 20 \mathrm{mmol}$ ) was mixed with 1,1,3,3-tetramethylguanidine ( $2.30 \mathrm{~g}, 20 \mathrm{mmol})$ in ethanol $(50 \mathrm{~mL})$. After being agitated vigorously at room temperature for $4 \mathrm{~h}$, the solvent in the mixture was evaporated and the crude [TMG] $\mathrm{BF}_{4}$ was left as viscous liquid. It was then washed with diethyl ether (three times with $20 \mathrm{~mL} /$ time) and dried at $80{ }^{\circ} \mathrm{C}$ for $12 \mathrm{~h}$ in vacuum to prepare pure [TMG] $\mathrm{BF}_{4}$ with the yield of $92.3 \%$. Similar procedures were used to prepare other [TMG]-based ILs as shown in Scheme 2 [32-34]. The synthesis of 1-butyl-3-methylimidazolium acetate ([BMIM]OAc) and ethanolamine tetrafluoroborate $\left([\mathrm{MEA}] \mathrm{BF}_{4}\right)$ was completed as described by Liu et al. [35] and Yuan et al. [36], respectively. The structures of the ionic liquids used in this study were characterized via ${ }^{1} \mathrm{H}$ NMR using a Bruker spectrometer and the results were listed in the Supplementary Materials. 


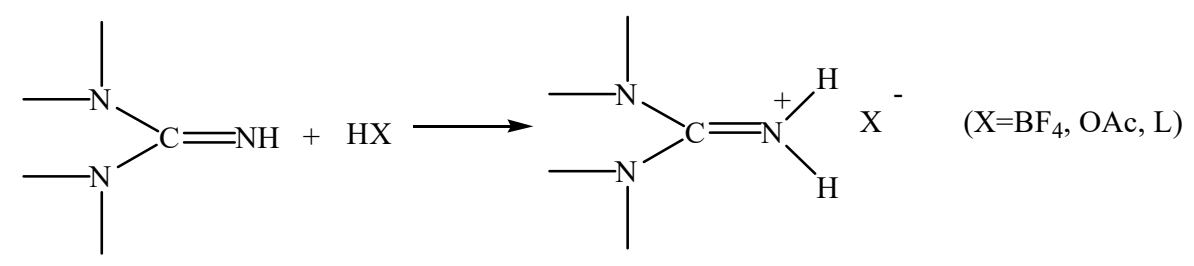

Scheme 2. Synthetic scheme for [TMG]-based ionic liquids (ILs).

\subsection{General Procedure for the Conversion of Carbohydrates to 5-HMF}

The conversion of carbohydrates into 5-HMF was carried out on $0.5 \mathrm{~g}$ carbohydrate mixed with $0.25 \mathrm{~g}$ catalyst (ILs) and $60 \mathrm{~mL}$ solvent in a 100-mL flask fitted with a condenser for a certain reaction time at $100{ }^{\circ} \mathrm{C} \sim 160^{\circ} \mathrm{C}$ in an oil-bath reactor.

After the reaction, the mixture was filtered through a $0.45-\mu \mathrm{m}$ pore size membrane and decanted into a volumetric flask using water as a diluent. 5-HMF and furfural were analyzed by HPLC (Agilent LC1260 infinity, Santa Clara, CA, USA) with a UV detector using a C18 column at $35{ }^{\circ} \mathrm{C}$ with methanol/water $(40 / 60, v / v)$ as an eluent at a flow rate of $0.6 \mathrm{~mL} / \mathrm{min}$. Glucose, cellobiose, levulinic acid (LA), formic acid (FA), and acetic acid were also analyzed by HPLC using a refractive index detector and a PL Hi-Plex $\mathrm{H}$ column at $65^{\circ} \mathrm{C}$ with $5 \mathrm{mM} \mathrm{H}_{2} \mathrm{SO}_{4}$ as an eluent at a flow rate of $0.6 \mathrm{~mL} / \mathrm{min}$. Fructose was determined by HPLC equipped with a refractive index detector and a PL Hi-Plex Pb column at $65^{\circ} \mathrm{C}$. The mobile phase was water at a flow rate of $0.6 \mathrm{~mL} / \mathrm{min}$.

The conversion of carbohydrates (mass\%) and the yield of 5-HMF (mass\%) were calculated on carbon basis as shown below:

Carbohydrates conversion (X, mass\%):

$$
X=\left(1-\frac{\text { Carbohydrates mass }}{\text { Starting mass of carbohydrates }}\right) \times 100 \%
$$

5-HMF yield ( $\mathrm{Y}$, mass $\%)$ :

$$
\mathrm{Y}=\frac{\text { Mass of } 5-\mathrm{HMF}}{\text { Starting mass of carbohydrates }} \times 100 \%
$$

\subsection{5-HMF Production from Carbohydrates with Different ILs as Catalysts}

As for glucose, the highest conversion of carbohydrate and yield of 5-HMF (58.32\% and $25.19 \%$, respectively) were obtained in the reaction catalyzed by [TMG] $\mathrm{BF}_{4}$. With [BMIM] $\mathrm{BF}_{4}$ as a catalyst, the conversion and yield were $5.15 \%$ and $3.44 \%$, respectively. These results demonstrate that with the same anion $\mathrm{BF}_{4}{ }^{-},[\mathrm{TMG}]^{+}$ion results in better catalytic activity compared to $[\mathrm{BMIM}]^{+}$. Although the glucose dehydration with $[\mathrm{MEA}] \mathrm{BF}_{4}$ as a catalyst gave a good conversion of glucose $(50.12 \%)$, the yield of 5-HMF was only $10.15 \%$, suggesting that glucose was probably converted into products other than 5-HMF. Furthermore, the transformation of other carbohydrates catalyzed by [TMG]BF under the same conditions are also listed in Table 1. In the previous study, the maximum yield of 5-HMF was 99.1\% obtained with 1-(3-sulfonicacid)propyl-3-methyl imidazolium phosphotungstate ([MIMPS $]_{3} \mathrm{PW}_{12} \mathrm{O}_{40}$ ) as a catalyst at $120{ }^{\circ} \mathrm{C}$ after $2 \mathrm{~h}$, using 2-butanol as a solvent [29]. In this study, 5-HMF yield increased quickly to $90 \%$ after $30 \mathrm{~min}$ and decreased rapidly at $160{ }^{\circ} \mathrm{C}$ in DMSO (conversion process not shown), which might have been caused by the polymerization and cross-polymerization of 5-HMF and intermediates forming tarry substances at a higher temperature and/or for a longer reaction time catalyzed by acidic ILs. Furthermore, a 5-HMF yield of $22.34 \%$ from sucrose with [MIMPS $]_{3} \mathrm{PW}_{12} \mathrm{O}_{40}$ was higher than that with [TMG] $\mathrm{BF}_{4}$ under the same conditions, but lower than those from other carbohydrates. The different between [MIMPS] ${ }_{3} \mathrm{PW}_{12} \mathrm{O}_{40}$ and [TMG] $\mathrm{BF}_{4}$ in carbohydrates conversion might due to the fact that acidic ILs exhibit much higher catalytic activity in fructose dehydration than alkaline ILs. 
Table 1. Dehydration of carbohydrates with different ILs ${ }^{\text {a }}$.

\begin{tabular}{|c|c|c|c|}
\hline Substrate & ILs & Conv. (\%) & 5-HMF Yield (\%) \\
\hline \multirow{12}{*}{ Glucose } & Control & 3.14 & 0.34 \\
\hline & [BMIM]OH & 17.48 & 1.40 \\
\hline & {$[\mathrm{BMIM}]_{2} \mathrm{CO}_{3}$} & 18.48 & 0.51 \\
\hline & [BMIM]PHCOO & 16.15 & 3.57 \\
\hline & {$[\mathrm{BMIM}]_{3} \mathrm{PW}_{12} \mathrm{O}_{40} \mathrm{~b}$} & 35.63 & 1.12 \\
\hline & {$[\mathrm{MIMPS}]_{3} \mathrm{PW}_{12} \mathrm{O}_{40} \mathrm{~b}$} & 71.34 & 4.23 \\
\hline & [BMIM]OAc & 2.14 & 0.11 \\
\hline & {$\left[\mathrm{BMIM} \mathrm{BF}_{4}\right.$} & 5.15 & 3.44 \\
\hline & {$\left[\mathrm{TMG} \mathrm{BF}_{4}\right.$} & 58.32 & 25.19 \\
\hline & [TMG]L & 30.14 & 19.15 \\
\hline & [TMG]OAc & 26.44 & 16.24 \\
\hline & {$[\mathrm{MEA}] \mathrm{BF}_{4}$} & 50.14 & 10.15 \\
\hline \multirow{2}{*}{ Fructose } & [TMG]BF 4 & 96.41 & 39.84 \\
\hline & {$[\mathrm{MIMPS}]_{3} \mathrm{PW}_{12} \mathrm{O}_{40}$} & 99.68 & 19.56 \\
\hline \multirow{2}{*}{ Sucrose } & {$[\mathrm{TMG}] \mathrm{BF}_{4}$} & 78.75 & 16.71 \\
\hline & {$[\mathrm{MIMPS}]_{3} \mathrm{PW}_{12} \mathrm{O}_{40}$} & 71.34 & 22.34 \\
\hline Cellobiose & {$\left[\mathrm{TMG} \mathrm{BF}_{4}\right.$} & 76.48 & 13.58 \\
\hline \multirow{2}{*}{$\begin{array}{l}\text { Microcrystalline } \\
\text { cellulose }^{\mathrm{c}}\end{array}$} & {$\left[{\mathrm{TMG}] \mathrm{BF}_{4}}\right.$} & - & 10.45 \\
\hline & {$[\mathrm{MIMPS}]_{3} \mathrm{PW}_{12} \mathrm{O}_{40}$} & - & 4.84 \\
\hline
\end{tabular}

a Conditions: substrate $(0.5 \mathrm{~g})$, ILs $(0.25 \mathrm{~g})$, dimethylsulfoxide $(60 \mathrm{~mL}), 160{ }^{\circ} \mathrm{C}, 2 \mathrm{~h} ;{ }^{\mathrm{b}}\left[\mathrm{BMIM}_{3} \mathrm{PW}_{12} \mathrm{O}_{40}\right.$ and [MIMPS] ${ }_{3} \mathrm{PW}_{12} \mathrm{O}_{40}$ were synthesized as in Reference [29]; ${ }^{\mathrm{c}} 5 \mathrm{wt} \% \mathrm{LiCl}-\mathrm{N}, \mathrm{N}$-dimethylacetamide.

\subsection{Alkaline IL [TMG]BF 4 -Catalyzed Conversion of Fructose and Glucose}

The conversion of fructose and glucose catalyzed by the alkaline IL ([TMG]BF 4 ) is demonstrated in Figure 1. It was obvious that all five products were increased as the reaction time was extended. Compared to furfural, levulinic acid (LA), formic acid, and acetic acid, 5-HMF was the major product as can be seen from Figure 1A,B. The highest yield of 5-HMF from fructose (Figure 1A) and glucose (Figure 1B) was $74.19 \%$ and $27.33 \%$, respectively. This is probably due to the basic property of the $[\mathrm{TMG}]^{+}$group, which may enhance the transformation from ketose form (fructose) more so than from aldose form (glucose) [30]. Additionally, the 5-HMF yield from glucose increased rapidly in the first $120 \mathrm{~min}$ and then remained essentially constant for a longer reaction time. On the other hand, the yield of formic acid enhanced obviously, indicating that the balance was achieved between the generation of 5-HMF and the degradation of glucose/5-HMF to formic acid and other byproducts as the reaction time increased. Formic acid might be the major degradation product of 5-HMF in this conversion system. 


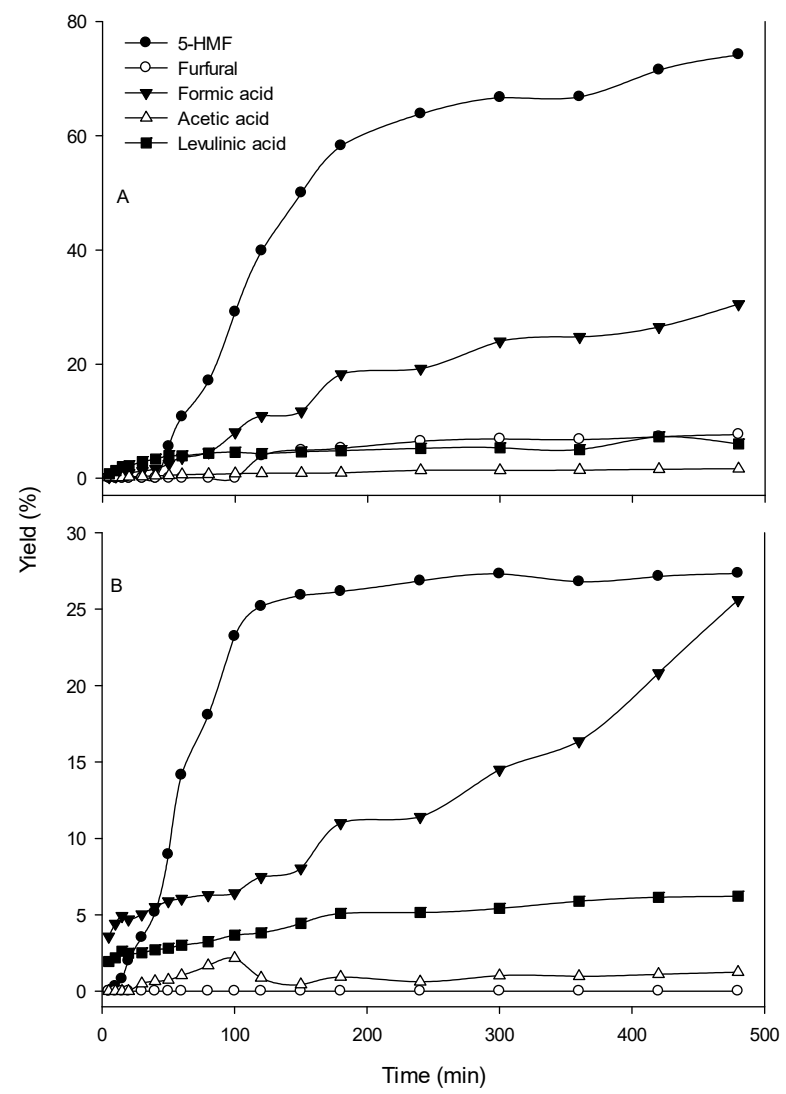

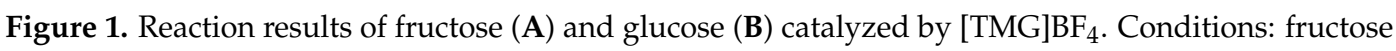
or glucose $(0.5 \mathrm{~g}), \mathrm{TMG}_{\mathrm{B}} \mathrm{BF}_{4}(0.25 \mathrm{~g})$, dimethylsulfoxide $(60 \mathrm{~mL}), 160{ }^{\circ} \mathrm{C}$.

\subsection{Conversion of MCC to 5-HMF with Different ILs as Catalysts}

Although the yield of 5-HMF from fructose is higher than that from glucose, fructose is much more expensive than glucose. If 5-HMF can be obtained from glucose or glucose-based saccharides such as cellulose, the most abundant biomass component in the nature, then the production cost will drop significantly. In the present study, MCC was tested, and Figure 2A illustrates the ILs containing different cations and anions that were used as catalysts in the conversion of MCC to 5-HMF. It is evident that the $\mathrm{BF}_{4}^{-}$ion resulted in a better reactivity compared to $\mathrm{L}^{-}$and $\mathrm{OAc}^{-}$with the same cation $\left([\mathrm{TMG}]^{+}\right)$. Meanwhile, the 5-HMF yield increased with the increasing alkalinity of IL, such as [TMG] $\mathrm{BF}_{4}$ compared to [MEA]BF 4 . As shown in Figure 2B, in the conversion of MCC into 5-HMF

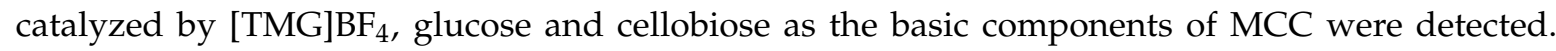
Moreover, the contents of glucose and cellobiose approached a maximum and then decreased. The reason for this could be that the generation of gluconic-based small molecules (glucose and cellobiose) as reaction intermediates in the conversion of MCC into 5-HMF catalyzed by [TMG] $\mathrm{BF}_{4}$ was probably more rapid than the transformation in the initial stage. The maximum glucose content was found to be $13.42 \%$ at $20 \mathrm{~min}$, followed by a sharp decrease after $20 \mathrm{~min}$. The glucose detected after $60 \mathrm{~min}$ was only $2.03 \%$, suggesting that the conversion of glucose into $5-\mathrm{HMF}$ is the committed step compared to the transformation of MCC into glucose-based small molecules in this IL-solvent system, similar to the result reported by Liu et al. [37]. Although the change in cellobiose content had a similar trend to that of glucose, as indicated in Figure 2B, the absolute quantity of cellobiose detected was much lower than that of glucose. However, this did not mean that there was only a small amount of cellobiose produced from MCC, since cellobiose can be hydrolyzed into glucose in the conversion process as shown in Figure 3. 

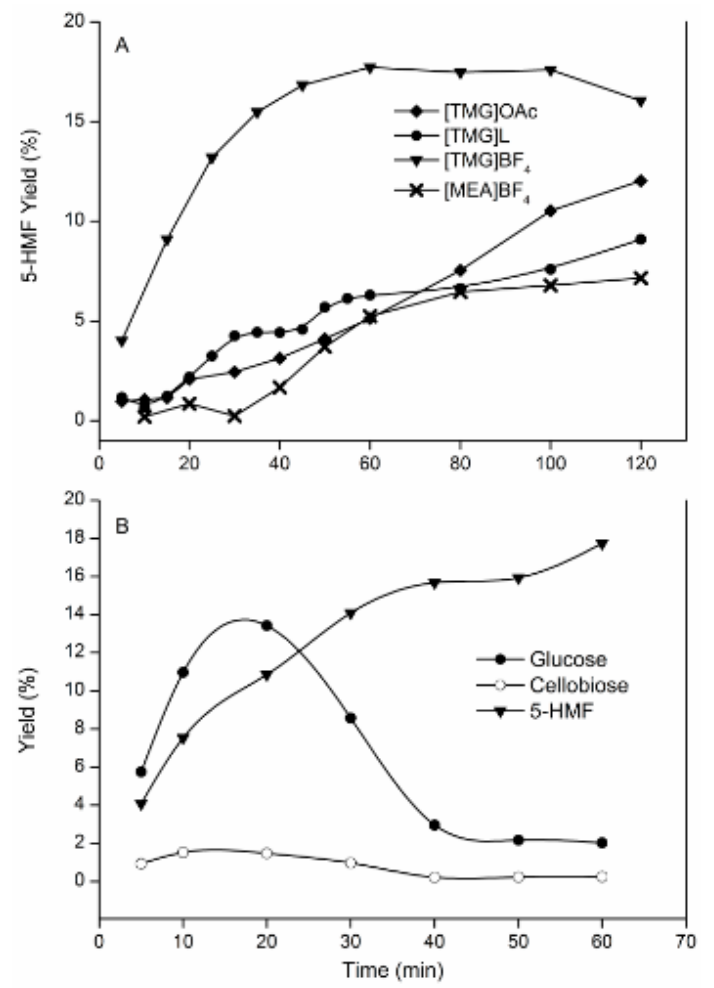

Figure 2. Reaction results of microcrystalline cellulose (MCC) into 5-HMF ((A) Conversion of MCC to 5-HMF using different ILs; (B) The yield of glucose and cellobiose in the conversion of MCC into 5-HMF

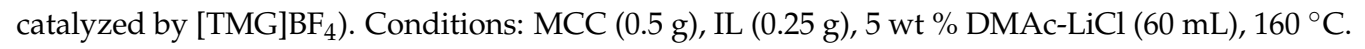

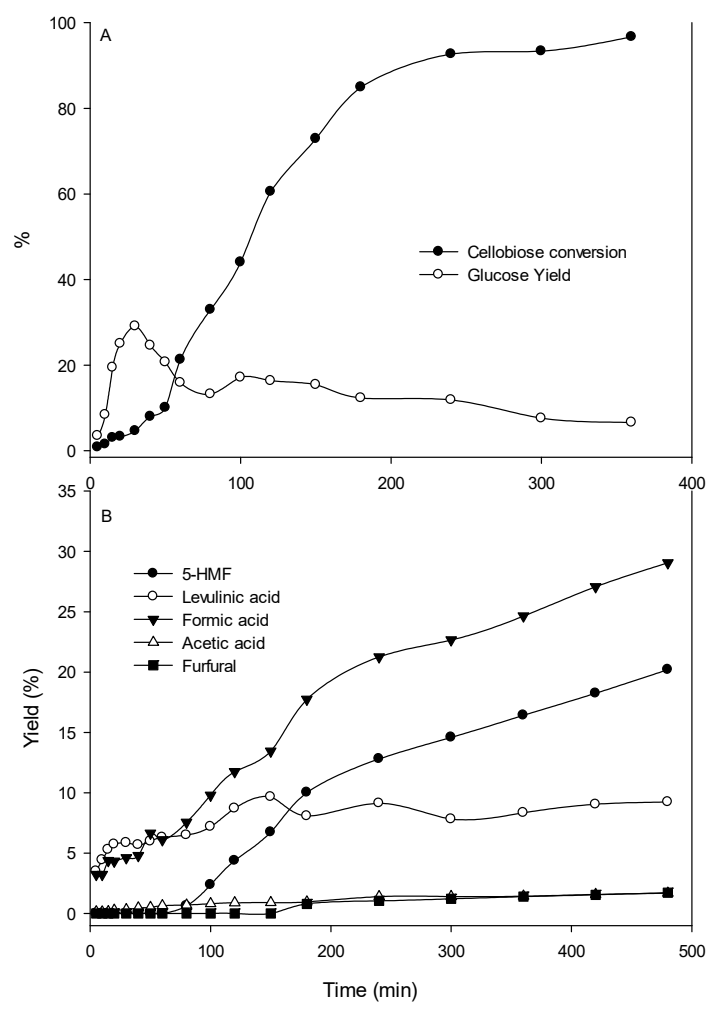

Figure 3. Reaction results of cellobiose catalyzed by $[\mathrm{TMG}] \mathrm{BF}_{4}((\mathbf{A})$ The cellobiose conversion and glucose yield in the conversion of cellobiose to 5-HMF; (B) The yield of the products catalyzed by

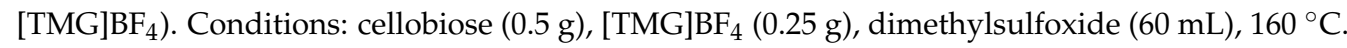


The hydrolysis of cellobiose and cellulose requires an acid medium, and the active hydrogen atom of imidazole can provide the acid medium as well as the acid hydrolyzate. In fact, in the transformation of cellobiose into 5-HMF, two steps are probably involved, namely the hydrolysis of the disaccharide into glucose and the dehydration of glucose. As described in Figure 3A, the conversion of cellobiose increased as the reaction time was prolonged. In the initial stage, glucose and 5-HMF yield increased rapidly as the reaction time was extended, with the maximum glucose content reaching $29.11 \%$ at $30 \mathrm{~min}$. It then decreased significantly with further reaction time, which was consistent with the results of the MCC conversion, as shown in Figure 2B. However, the detected glucose content in the cellobiose conversion process was much higher than that in the MCC conversion process. Furthermore, the intermediates generated trends similar to those reported in the literature [2]. In addition, formic acid was observed as the major product from cellobiose with the yield of $29.05 \%$, shown in Figure 3B. The 5-HMF yield continued to increase in all of the reaction times, and reached $20.20 \%$ at $480 \mathrm{~min}$. It is worth noting that the maximum yield of formic acid from fructose (Figure $1 \mathrm{~A}$ ), glucose (Figure 1B), and cellobiose (Figure 3B) obtained with the same reaction time were $30.52 \%$, $25.60 \%$, and $29.05 \%$, respectively, indicating that formic acid could be another potential product other than 5-HMF. Although according to Scheme 1, the amounts of levulinic and formic acids must be equimolar, $\gamma$-valerolactone may be produced by the hydrogenation of levulinic acid, which would result in a higher yield of formic acid than that of levulinic acid after HPLC detection.

\subsection{Possible Pathway of Conversion of Carbohydrates to 5-HMF with Alkaline ILs as Catalysts}

A possible pathway of the conversion of carbohydrates to 5-HMF catalyzed by [TMG] $\mathrm{BF}_{4}$ was suggested and is shown in Figure 4. During the conversion of MCC, glucose can be produced either by the direct hydrolysis of MCC, or by the catalysis degradation of cellobiose which was formed as an intermediate from MCC, which was why glucose and cellobiose were detected at the same time, as shown in Figure 2B. Additionally, in the conversion of MCC, glucose was found to be much higher than cellobiose. The maximum glucose level of $13.42 \%$ at $20 \mathrm{~min}$ was obtained, followed by a sharp decrease in the next $20 \mathrm{~min}$, indicating that the conversion of glucose into 5-HMF is probably the committed step in the transformation of MCC catalyzed by [TMG] $\mathrm{BF}_{4}$. Moreover, 5-HMF was the triple dehydration product of hexose. An alkaline catalyst can promote glucose to be isomerized to fructose, which is known as the Lobry-de Bruyn-van Ekenstein transformation. Thus, [TMG]BF 4 is clearly an effective catalyst, regarded as a key step in the conversion of glucose into 5-HMF [38-40]. On the other hand, compared to glucopyranose ( $\alpha$-D-glucopyranose and $\beta$-D-glucopyranose), the structure of glucofuranose ( $\alpha$-D-glucofuranose and $\beta$-D-glucofuranose) is more suitable for the synthesis of 5-HMF. Moderate alkalinity of a system can contribute to the formation of hydrogen bonding between $\left[\mathrm{TMG}_{\mathrm{BF}}\right.$ and the isomeride, which facilitates the nucleophilic attack of the nitrogen on the electrophilic carbon of the cyano group to give an intermediate, further converted into 5-HMF [19]. 


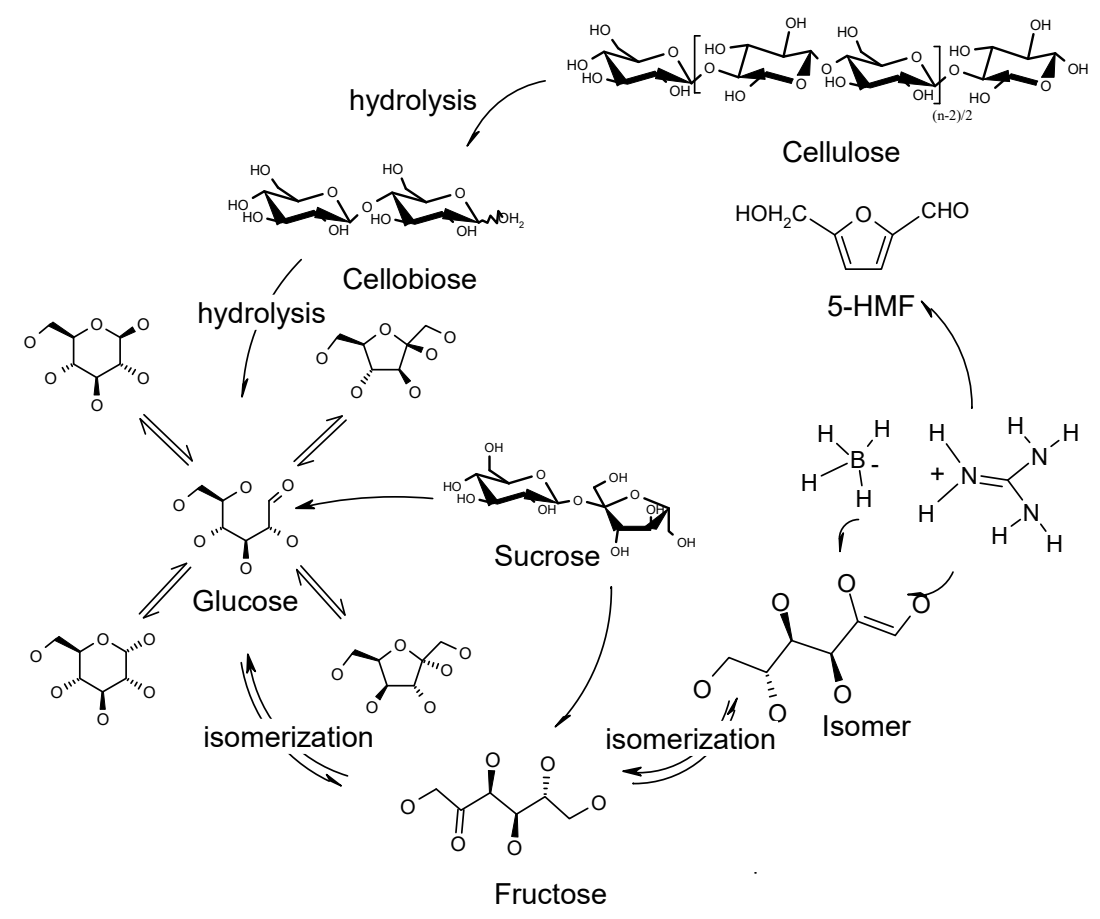

Figure 4. Possible pathway of the conversion of carbohydrates to 5-HMF with [TMG]BF 4 as a catalyst.

\section{Conclusions}

In summary, several platform chemicals were produced in the conversion of carbohydrates catalyzed by ILs in normal organic solvents. Compared to the conventional IL system catalyzed by salt, this IL self-catalyst dehydration process showed higher efficiency and yield in carbohydrates conversion, which could be attributed to the synergy of the cation/anion presenting in the ionic liquid. Of the alkaline ILs employed, [TMG] ${ }^{+}$-based exhibited better activity and 5-HMF was the major product achieved through the reaction. Moreover, the conversion of glucose into 5-HMF is probably the committed step in the transformation of MCC catalyzed by [TMG] $\mathrm{BF}_{4}$.

Supplementary Materials: Supplementary Materials are available online at www.mdpi.com/2073-4344/7/9/ $245 /$ s1.

Acknowledgments: The work was financially supported by the National Natural Science Foundation of China (No. 21206008).

Author Contributions: Yongshui Qu and Jie Zhang conceived and designed the experiments; Xiaojia Du performed the experiments; Xiaojia Du and Yuehai Wang analyzed the data; Yuehai Wang contributed analysis tools; Xiaojia Du wrote the paper.

Conflicts of Interest: The authors declare no conflict of interest.

\section{References}

1. Corma, A.; Iborra, S.; Velty, A. Chemical routes for the transformation of biomass into chemicals. Chem. Rev. 2007, 107, 2411-2502. [CrossRef] [PubMed]

2. Chen, W.H.; Ye, S.C.; Sheen, H.K. Hydrolysis characteristics of sugarcane bagasse pretreated by dilute acid solution in a microwave irradiation environment. Appl. Energy 2012, 93, 237-244. [CrossRef]

3. Dwidar, M.; Lee, S.; Mitchell, R.J. The production of biofuels from carbonated beverages. Appl. Energy 2012, 100, 47-51. [CrossRef]

4. Ståhlberg, T.; Sørensen, M.G.; Riisager, A. Direct conversion of glucose to 5-(hydroxymethyl)furfural in ionic liquids with lanthanide catalysts. Green Chem. 2010, 12, 321-325. [CrossRef]

5. Román-leshkov, Y.; Barrett, C.J.; Liu, Z.Y.; Dumesic, J.A. Production of dimethylfuran for liquid fuels from biomass-derived carbohydrates. Nature 2007, 447, 982-985. [CrossRef] [PubMed] 
6. Putten, R.J.V.; Waal, J.C.V.D.; Jong, E.D.; Rasrendra, C.B.; Heeres, H.J.; Vries, J.G.D. Hydroxymethylfurfural, a versatile platform chemical made from renewable resources. Chem. Rev. 2013, 113, 1499-1597. [CrossRef] [PubMed]

7. Werpy, T.; Petersen, G.; Aden, A.; Bozell, J.; Holladay, J.E.; White, J.; Manheim, A.; Elliott, D.C.; Lasure, L.; Jones, S. Top Value Added Chemicals from Biomass, Vol. 1, Results of Screening for Potential Candidates from Sugars and Synthesis Gas; Technical Report; US Department of Energy: Washington, DC, USA, 2004.

8. Rosatella, A.A.; Simeonov, S.P.; Frade, R.F.M.; Afonso, C.A.M. 5-hydroxymethylfurfural (HMF) as a building block platform: Biological properties, synthesis and synthetic applications. Green Chem. 2011, 13, 754-793. [CrossRef]

9. Climent, M.J.; Corma, A.; Iborra, S. Converting carbohydrates to bulk chemicals and fine chemicals over heterogeneous catalysts. Green Chem. 2011, 13, 520-540. [CrossRef]

10. Hu, S.Q.; Zhang, Z.F.; Song, J.L.; Zhou, Y.X.; Han, B.X. Efficient conversion of glucose into 5-hydroxymethylfurfural catalyzed by a common Lewis acid $\mathrm{SnCl}_{4}$ in ionic liquid. Green Chem. 2009, 11, 1746-1749. [CrossRef]

11. Li, W.J.; Zhang, Z.F.; Han, B.X.; Hu, S.Q.; Song, J.L.; Xie, Y.; Zhou, X.S. Switching the basicity of ionic liquids by $\mathrm{CO}_{2}$. Green Chem. 2008, 10, 1142-1145. [CrossRef]

12. Saha, B.; Abu-Omar, M.M. Advances in 5-hydroxymethylfurfural production from biomass in biphasic solvents. Green Chem. 2014, 16, 24-38. [CrossRef]

13. Agirrezabal-Telleria, I.; Gandarias, I.; Arias, P.L. Heterogeneous acid-catalysts for the production of furan-derived compounds (furfural and hydroxymethylfurfural) from renewable carbohydrates: A review. Catal. Today 2014, 234, 42-58. [CrossRef]

14. Wang, T.F.; Nolte, M.W.; Shanks, B.H. Catalytic dehydration of $\mathrm{C}_{6}$ carbohydrates for the production of hydroxymethylfurfural (HMF) as a versatile platform chemical. Green Chem. 2014, 16, 548-572. [CrossRef]

15. Lima, S.; Neves, P.; Antunes, M.M.; Pillinger, M.; Ignatyev, N.; Valente, A.A. Conversion of mono/di/polysaccharides into furan compounds using 1-alkyl-3-methylimidazolium ionic liquids. Appl. Catal. A Gen. 2009, 363, 93-99. [CrossRef]

16. Yong, G.; Zhang, Y.G.; Ying, J.Y. Highly efficient catalytic system for the selective production of hydroxylmethylfurfural from glucose and fructose. Angew. Chem. Int. Ed. 2008, 47, 9345-9348. [CrossRef] [PubMed]

17. Zhao, H.B.; Holladay, J.E.; Brown, H.; Zhang, Z.C. Metal chlorides in ionic liquid solvents convert sugars to 5-Hydroxymethylfurfural. Science 2007, 316, 1597-1600. [CrossRef] [PubMed]

18. Shi, C.Y.; Zhao, Y.L.; Xin, J.Y.; Wang, J.Q.; Lu, X.M.; Zhang, X.P.; Zhang, S.J. Effect of cations and anions of ionic liquids on the production of 5-hydroxymethylfurfural from fructose. Chem. Commun. 2012, 48, 4103-4105. [CrossRef] [PubMed]

19. Shi, N.; Liu, Q.Y.; Zhang, Q.; Wang, T.J.; Ma, L.L. High yield production of 5-hydroxymethylfurfural from cellulose by high concentration of sulfates in biphasic system. Green Chem. 2013, 15, 1967-1974. [CrossRef]

20. Zuo, M.; Le, K.; Li, Z.; Jiang, Y.T.; Zeng, X.H.; Tang, X.; Sun, Y.; Lin, L. Green process for production of 5-hydroxymethylfurfural from carbohydrates with high purity in deep eutectic solvents. Ind. Crop. Prod. 2017, 99, 1-6. [CrossRef]

21. Carniti, P.; Gervasini, A.; Marzo, M. Absence of expected side-reactions in the dehydration reaction of fructose to HMF in water over niobic acid catalyst. Catal. Commun. 2011, 12, 1122-1126. [CrossRef]

22. Despax, S.; Maurer, C.; Estrine, B.; Bras, J.L.; Hoffmann, N.; Marinkovic, S.; Muzart, J. Fast and efficient DMSO-mediated dehydration of carbohydrates into 5-hydroxymethyfurfural. Catal. Commun. 2014, 51, 5-9. [CrossRef]

23. Zhang, Z.H.; Zhao, Z.B.K. Production of 5-hydroxymethylfurfural from glucose catalyzed by hydroxyapatite supported chromium chloride. Bioresour. Technol. 2011, 102, 3970-3972. [CrossRef] [PubMed]

24. Li, H.; Zhang, Q.Y.; Liu, X.F.; Chang, F.; Zhang, Y.P.; Xue, W.; Yang, S. Immobilizing $\mathrm{Cr}^{3+}$ with $^{2}$ $\mathrm{SO}_{3} \mathrm{H}$-functionalized solid polymeric ionic liquids as efficient and reusable catalysts for selective transformation of carbohydrates into 5-hydroxymethylfurfural. Bioresour. Technol. 2013, 144, $21-27$. [CrossRef] [PubMed]

25. Zhou, L.L.; Liang, R.J.; Ma, Z.W.; Wu, T.H.; Wu, Y. Conversion of cellulose to HMF in ionic liquid catalyzed by bifunctional ionic liquids. Bioresour. Technol. 2013, 129, 450-455. [CrossRef] [PubMed] 
26. Tong, X.L.; Li, Y.D. Efficient and selective dehydration of fructose to 5-hydroxymethylfurfural catalyzed by brønsted-acidic ionic liquids. ChemSusChem 2010, 3, 350-355. [CrossRef] [PubMed]

27. Tian, G.; Tong, X.L.; Cheng, Y.; Xue, S. Tin-catalyzed efficient conversion of carbohydrates for the production of 5-hydroxymethylfurfural in the presence of quaternary ammonium salts. Carbohydr. Res. 2013, 370, 33-37. [CrossRef] [PubMed]

28. Qu, Y.S.; Huang, C.P.; Song, Y.L.; Zhang, J.; Chen, B.H. Efficient dehydration of glucose to 5-hydroxymethylfurfural catalyzed by the ionic liquid, 1-hydroxyethyl-3-methylimidazolium tetrafluoroborate. Bioresour. Technol. 2012, 121, 462-466. [CrossRef] [PubMed]

29. Qu, Y.S.; Huang, C.P.; Zhang, J.; Chen, B.H. Efficient dehydration of fructose to 5-hydroxymethylfurfural catalyzed by a recyclable sulfonated organic heteropolyacid salt. Bioresour. Technol. 2012, 106, 170-172. [CrossRef] [PubMed]

30. Qu, Y.S.; Huang, C.P.; Song, Y.L.; Zhang, J.; Chen, B.H. Alkaline ionic liquids as catalysts: A novel and green process for the dehydration of carbohydrates to give 5-hydroxymethylfurfural. Ind. Eng. Chem. Res. 2012, 51, 13008-13013. [CrossRef]

31. Berg, R.W.; Riisager, A.; Fehrmann, R. Formation of an ion-pair molecule with a single $\mathrm{NH}^{+} \ldots \mathrm{Cl}^{-}$hydrogen bond: Raman spectra of 1,1,3,3-tetramethylguanidinium chloride in the solid state, in solution, and in the vapor phase. J. Phys. Chem. A 2008, 112, 8585-8592. [CrossRef] [PubMed]

32. Gabhane, J.; William, S.P.M.P.; Vaidya, A.N.; Mahapatra, K.; Chakrabarti, T. Influence of heating source on the efficacy of lignocellulosic pretreatment-A cellulosic ethanol perspective. Biomass Bioenergy 2011, 35, 96-102. [CrossRef]

33. Huang, J.; Riisager, A.; Berg, R.W.; Fehrmann, R. Tuning ionic liquids for high gas solubility and reversible gas sorption. J. Mol. Catal. A Chem. 2008, 279, 170-176. [CrossRef]

34. Zhu, A.L.; Jiang, T.; Wang, D.; Han, B.X.; Liu, L.; Huang, J.; Zhang, J.C.; Sun, D.H. Direct aldol reactions catalyzed by 1,1,3,3-tetramethylguanidine lactate without solvent. Green Chem. 2005, 7, 514-517. [CrossRef]

35. Liu, F.S.; Li, L.; Yu, S.T.; Lv, Z.G.; Ge, X.P. Methanolysis of polycarbonate catalyzed by ionic liquid [Bmim][Ac]. J. Hazard. Mater. 2011, 189, 249-254. [CrossRef] [PubMed]

36. Yuan, X.L.; Zhang, S.J.; Lu, X.M. Hydroxyl ammonium ionic liquids: Synthesis, properties, and solubility of $\mathrm{SO}_{2}$. J. Chem. Eng. Data 2007, 52, 596-599. [CrossRef]

37. Liu, R.L.; Chen, J.Z.; Huang, X.; Chen, L.M.; Ma, L.L.; Li, X.J. Conversion of fructose into 5-hydroxymethylfurfural and alkyl levulinates catalyzed by sulfonic acid-functionalized carbon materials. Green Chem. 2013, 15, 2895-2903. [CrossRef]

38. Moreau, C.; Lecomte, J.; Roux, A. Determination of the basic strength of solid catalysts in water by means of a kinetic tracer. Catal. Commun. 2006, 7, 941-944. [CrossRef]

39. Moreau, C.; Durand, R.; Roux, A.; Tichit, D. Isomerization of glucose into fructose in the presence of cation-exchanged zeolites and hydrotalcites. Appl. Catal. A Gen. 2000, 193, 257-264. [CrossRef]

40. Lecomte, J.; Finiels, A.; Moreau, C. Kinetic study of the isomerization of glucose into fructose in the presence of anion-modified hydrotalcites. Starch 2002, 54, 75-79. [CrossRef]

(c) 2017 by the authors. Licensee MDPI, Basel, Switzerland. This article is an open access article distributed under the terms and conditions of the Creative Commons Attribution (CC BY) license (http:/ / creativecommons.org/licenses/by/4.0/). 